\title{
Participatory Mapping and Visualization of Local Knowledge: An Example from Eberbach, Germany
}

\author{
Carolin Klonner $^{1}\left([) \cdot\right.$ Tomás J. Usón $^{2} \cdot$ Nicole Aeschbach $^{1}\left(\right.$ C) $\cdot$ Bernhard Höfle $^{1}$ (i)
}

Accepted: 3 June 2020/ Published online: 30 October 2020

(C) The Author(s) 2020

\begin{abstract}
A rise in the number of flood-affected people and areas has increased the interest in new methods and concepts that account for this change. Citizens are integrated into disaster risk reduction processes through participatory approaches and can provide valuable up-to-date local knowledge. During a field study in Eberbach (BadenWuerttemberg, Germany) sketch maps and questionnaires were used to capture local knowledge about flooding. Based on a previous study on urban flooding in Santiago de Chile, the tools were adapted and applied to river flooding in the city of Eberbach, which is regularly flooded by the Neckar River, a major river in southwest Germany. The empirical database of the study comprises 40 participants in the study area and 40 in a control area. Half of the participants in each group are residents and half are pedestrians. Purposive sampling was used, and the questionnaires aimed to gather demographic information and explore what factors, such as property, influence the risk perception of the study participants. The results show that residents identify a larger spatial area as at risk than pedestrians, and owning property leads to higher risk awareness. The flood type influenced the choice of the base maps for the sketch maps. For river flooding, one map with an overview of the area was sufficient, while for urban flooding a second map with more details of the area also
\end{abstract}

Carolin Klonner

c.klonner@uni-heidelberg.de

Institute of Geography, Heidelberg University, 69120 Heidelberg, Germany

2 Institute of European Ethnology and IRI THESys (Integrative Research Institute on Transformations of HumanEnvironment Systems), Humboldt University of Berlin, 10117 Berlin, Germany enables the marking of small streets. The information gathered can complement authoritative data such as from flood models. This participatory approach also increases the communication and trust between local governments, researchers, and citizens.

Keywords Disaster risk reduction · Flooding - Local knowledge $\cdot$ Participatory approach $\cdot$ Sketch maps Volunteered geographic information

\section{Introduction}

An increase in the number of people affected by floods has raised attention to disaster risk reduction (DRR) research and strategies on an international level, for example the Hyogo Framework for Action 2005-2015 and the Sendai Framework for Disaster Risk Reduction 2015-2030 (UNDRR 2019a). New methods and concepts that account for this increase in flood issues have gained more attention, for example, up-to-date and local geo-located information provided by citizens. In this way the affected population can also increase their risk awareness, take responsibility for their own preparedness, and take part in the governance structures (Usón et al. 2016).

There are different forms of knowledge. The nomads Moken of the Andaman Sea, for example, relied on their indigenous knowledge about the legend of the Laboon and survived the 2004 tsunami. The story about "The wave that eats people" states that the sea goes back and the singing of the cicadas stops before a tsunami arrives. This was happening before the tsunami in 2004 and it was recognized by one of the Moken members, who warned everyone. The whole community was able to get to higher ground before the first wave struck (Singh 2011). 
Many citizens of an area at risk, particularly the ones who have already lived there for a long time, have a lot of knowledge about historic events in their neighborhood, and this knowledge gives an indication of their general awareness of risk and how they are prepared for an emergency (Wagner 2007). However, this knowledge is often hidden and, therefore, not applied in current disaster management strategies. Hence, two research questions need to be answered in order to allow for an application of this knowledge in disaster management. First, how can local knowledge be formalized and preserved for future generations? Second, how is it possible to put this local knowledge into a digitized and georeferenced form in order to combine it with other types of digital data and technical devices employed by, for example, disaster management? Such approaches allow for improved preparedness before a natural hazard occurs and can limit devastating consequences. A catastrophe might even be mitigated with combined methods and knowledge.

Knowledge is a broad term and can be understood in different ways. Therefore, we need to specify the scope of the type of knowledge we refer to as local knowledge in our study. Polanyi (1966) discussed implicit and explicit knowledge in his book The Tacit Dimension. Implicit or tacit knowledge refers to the "know how," for example, a person's ability or action-inherent knowledge, which does not have verbal forms to be articulated: "we can know more than we can tell" (Polanyi 1966, p. 4). In contrast, explicit knowledge refers to "knowing that," such as about a special issue. This knowledge can be articulated and related to local knowledge, because the focus is on content, which can be verbally expressed. However, this verbal expression often does not occur; thus, although we have explicit knowledge, it is not seen as explicitly available. Therefore, a first step in the integration of citizens into disaster management structures is the focus on disclosure methods to allow for expressing this knowledge in a way in which it can be provided and understood by a broad audience. We use the term local knowledge to emphasize the focus on knowledge that refers to citizens' daily lives in their neighborhood. Apart from the methods of expressing this knowledge of the "sender," that is, the local population, we also need to consider the information within the setting because local knowledge strongly depends on context. The local government or a disaster management center, the "recipient," that is, a disaster management professional or a member of the local government can then interpret the information and act accordingly.

Yumagulova and Vertinsky (2019) divided knowledge into four different types based on various references: Scientific (or expert) knowledge, local knowledge, bureaucratic (administrative) knowledge, and indigenous knowledge. According to the authors, local knowledge relates to a specific context and the experiences of this place, and indigenous knowledge describes experiences and traditions passed on to the next generations. In our study we will refer to local knowledge in the sense of a combination of the concepts of local and indigenous knowledge presented by Yumagulova and Vertinsky (2019).

When talking about ways to include local knowledge, volunteered geographic information (VGI) comes into play. The term was coined by Goodchild (2007) to refer to user-generated content (UGC) in the field of geography. Due to the development of technical devices, such as smartphones, lay people are now able to contribute geographic data as well, if they have the necessary digital equipment and knowledge. Elwood et al. (2012) pointed out the increase of a digital divide because elderly people or people with low income may not have the means or knowledge to be able to contribute data. This fact has to be kept in mind when developing participatory methods.

There has been a significant increase in projects that involve VGI within disaster management in the last years. But as Horita et al. (2013) and Klonner et al. (2016b) pointed out, most of these projects refer to the response to disasters. Recent research reveals that it is also possible to include data provided by citizens into the mitigation and preparedness phase, such as for hydrodynamic models (Dorn et al. 2014; Assumpção et al. 2018). Local information from citizens can be shared and up-to-date maps can be produced before a disaster (Soden et al. 2014). Such actively volunteered and explicitly geographic information (Craglia et al. 2012) can be collected and shared on different digital devices. Ferster and Coops (2014), for example, used a smartphone app, which not only allowed local citizens to collect information about forest fuel in their neighborhood but also increased the awareness of potential risks in this area. The issue of awareness raising is very important because in many areas with high risk citizens have low risk perception and are therefore not taking adequate protective measures (Aerts et al. 2018). Aerts et al. pointed out "[...] that some of the factors [...] (for example, flood experience and communication by media) lead to a high perception of flood risks, and that people with high risk perceptions implement DRR activities at a relatively higher rate than those with lower risk perceptions" (Aerts et al. 2018, p. 195, with reference to Botzen et al. 2009 and Bubeck et al. 2012). Shi et al. (2016) referred to knowledge as a cognitive perspective of risk perception within the context of climate change. They emphasized that knowledge and beliefs influence attitudes and the risk perception of a topic, which in turn influences specific behaviors and intentions (Shi et al. 2016). Thus, knowledge about characteristics, causes, and consequences is related to the concern about climate change and behavior 
changes. They also found that individual values influence the concern about climate change (Shi et al. 2016). Therefore, by formalizing citizens' local knowledge about flooding, we might be able to draw conclusions about their risk perceptions and their intentions. This aligns with Haworth et al. (2018), who indicated that local knowledge is one of the factors that influences community disaster resilience, and they regard resilience as a crucial part of DRR. The United Nations Office for Disaster Risk Reduction (UNDRR) (2019b) defines resilience as:

The ability of a system, community or society exposed to hazards to resist, absorb, accommodate, adapt to, transform and recover from the effects of a hazard in a timely and efficient manner, including through the preservation and restoration of its essential basic structures and functions through risk management.

The resilience-building process is supported by the information flow between different stakeholders (Marana et al. 2018); and the local knowledge of the citizens, for example, is made available to the local governments by participatory methods.

An important means of knowledge exchange can be based on maps, although a discrepancy in power relations should be considered given that such maps might not be readable by all stakeholders. Hazard maps, for example, are based on Western standards of semiology and guidelines, and might not be understandable by and useful to some affected communities, while informative maps crafted by local communities about risk perception or vulnerability, for example, might not be georeferenced and scaled (Gaillard and Mercer 2013). There have already been different approaches to integrating and visualizing these kinds of data in a geographic information system (GIS); these vary from methods for paper-based sketch maps that include manual or automated georeferencing to approaches that are digital right from the beginning and participants can draw directly on a digital device. Mental maps are based on blank sheets on which participants draw their mental images. In contrast to this base of blank sheets, sketch maps are based on geographic maps. In this way the participants' marking has a spatial reference and can be used for further computer-based spatial analyses.

O'Neill et al. (2015), Cheung et al. (2016), and Klonner et al. (2018) successfully applied sketch maps, mainly to capture experiences with flooding and the flood risk perception of the local population. However, research about factors that influence the information captured by sketch maps and clear guidelines for the application of sketch map approaches are still missing (Curtis et al. 2014); only recently has this research received more interest. Klonner et al. (2018) studied some influencing factors such as the place of living of the participants or the acquisition scale of the base maps of the sketch maps.

To realize the full potential of the work together with citizens, Birkmann and von Teichman (2010) pointed out that it is important to combine local and expert knowledge and to have good communication between the different actors within multidisciplinary work, for example, on a platform for knowledge management. Klonner et al. (2018) analyzed the potential of participative methods for risk analysis of flooding in an urban setting of Santiago de Chile. However, similar to the findings of Reichel and Frömming (2014), the lack of communication between citizens and the different levels of official institutions is identified, which hinders the acceptance of local knowledge in disaster management (Usón et al. 2016). This makes it even more evident that communication and information exchange need to be improved.

The integration of local knowledge into hazard management makes it possible to allow for an adaptation of the local population to prospective environmental changes and to cope with them more easily (Reichel and Frömming 2014). It is essential to gather local knowledge within its context as "the strategies to prevent, respond to, and remember natural hazards also differ depending on the given social and cultural context" (Reichel and Frömming 2014, p. 52). In order to develop effective flood protection measures and strategies, in most cases, target knowledge and transformation knowledge are of extremely great value in addition to systems knowledge (Hirsch Hadorn et al. 2008). Thus, it becomes clear that the scientific treatment of the challenges in the context of flood events requires not only interdisciplinary but also transdisciplinary research approaches. In this setting, the study participants are both potentially affected and data providers at the same time.

Studies based on participatory approaches for flood hazard analysis focus mainly on one specific geographic area for which they were developed and tested. In our research we want to go a step further and apply the methods of sketch maps accompanied by questionnaires in another cultural context and for another flood type to investigate whether the methods that were applied successfully in Chile (Klonner et al. 2016a) can also be applied to a different flood type and a different setting. Santiago de Chile is affected by urban flooding, while Eberbach, Germany, has to face river flooding. We developed our methods further for the German setting and for the different flood types and the applicability is tested in the case study in Eberbach. We aimed at integrating the flood-affected population into the DRR process and to capture information related to the specific local context. In that way, the citizens' willingness to take preventive actions can be increased, valuable information for analyses 
within DRR is provided, and further mitigation and preparedness measures can be implemented.

\section{Study Area}

When it comes to assessing citizens' local knowledge about floods, a region with regular flooding is required as a research area (Fig. 1). Due to our objective to develop our methods further for the application to river flooding, we decided to conduct our study in Eberbach in the Federal State of Baden-Wuerttemberg, Germany. The city has around 15,000 inhabitants and is prone to river flooding (Eberbach 2018b). This study area also enables the comparison of the application of the approach to a city in Chile and a German city. Within the city of Eberbach, we selected an overview area that included the study area in the flood-prone city center and a residential control area not affected by flooding from the Neckar River (Fig. 1).

Eberbach is located next to the Neckar River and is a popular tourist destination due to its historic old town and the beautiful countryside shaped by the Neckar. However, this famous river is not only a desirable feature of the city but it also harbors dangers. Several flood level markings in the city bear witness to the long history of extreme floods, and specific street signs are reminders of the other face of the Neckar. The city has a special alarm plan that informs the citizens about the level of the Neckar with different sounds from the alarm system so that citizens can take personal preventive actions accordingly. The local authorities also take action according to this plan (Eberbach 2018a). Severe floods occurred in 1993 and 1994, which affected nearly the whole study area, and several mitigation measures have been installed since (Figs. 2, 3).

\section{Methods}

In our study we aimed at capturing the local population's knowledge about flooding, with the help of an easy-to-use tool that also includes marginalized people without the required technical knowledge or digital equipment, who would be excluded in a more digital media-oriented approach (Elwood et al. 2012). The local knowledge is formalized by the drawing of a mental image. These drawings are based on maps, since we wanted to gather and visualize spatial information. In this way the information provided can be used directly for further spatial analyses. A
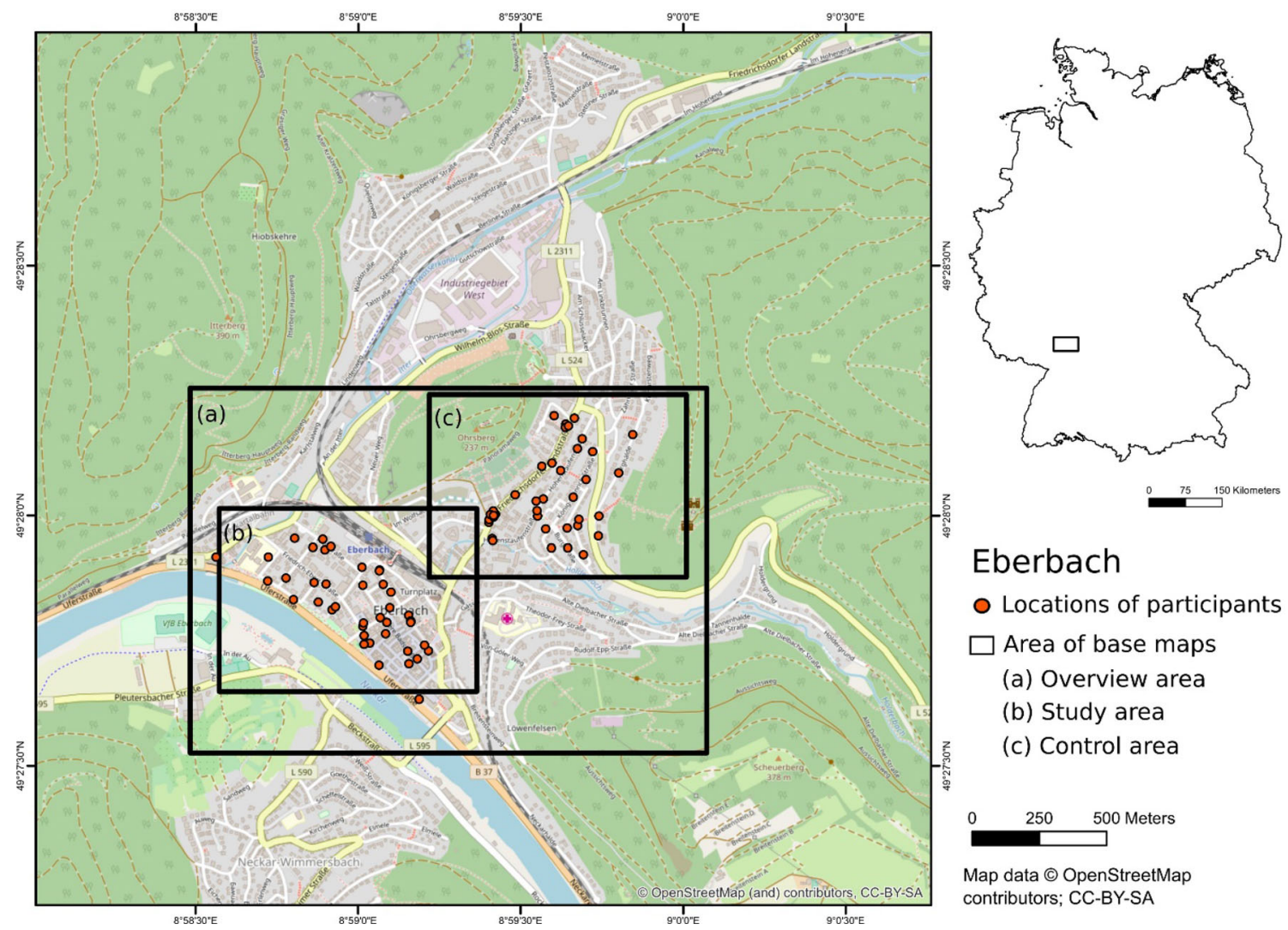

(a) Overview area

(b) Study area

(c) Control area

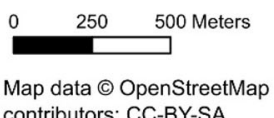

Map data (C) OpenStreetMap contributors; CC-BY-SA

Fig. 1 Eberbach is located about $30 \mathrm{~km}$ northeast of Heidelberg in southwestern Germany. The base maps for the sketch maps include an overview area (a), the study area (b), and a control area (c). Orange dots indicate the participants' locations during the survey in the study area and the control area, respectively 


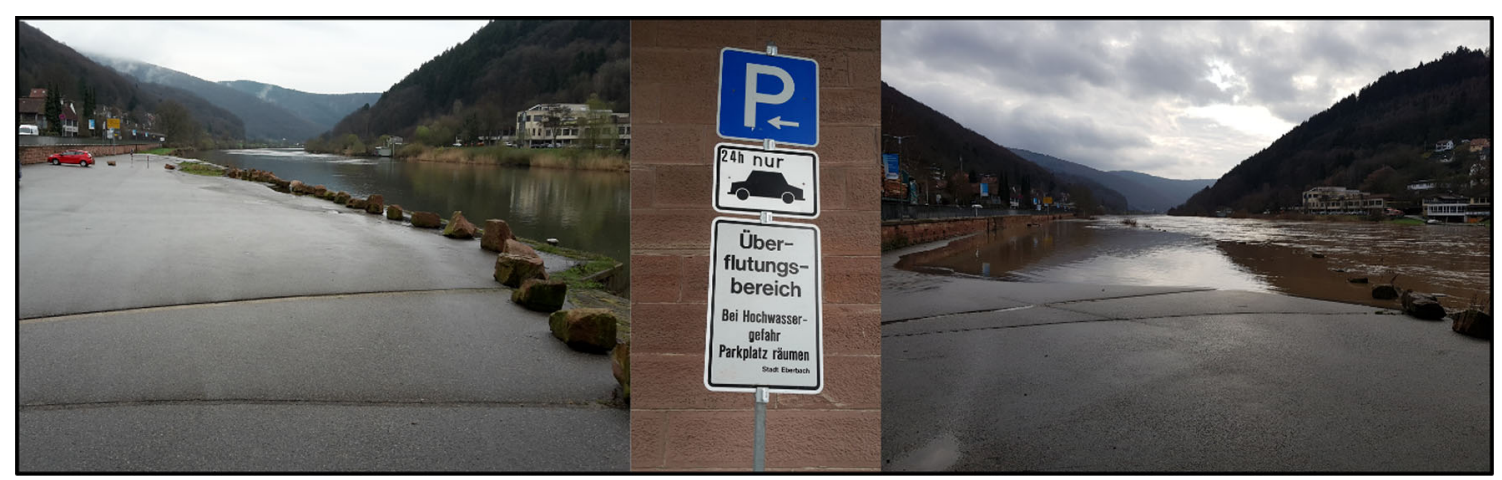

Fig. 2 Parking area by the Neckar River in Eberbach, Germany. The sign states that it is a flood-prone area that needs to be cleared as soon as a flood warning occurs. Photographs by C. Klonner, Eberbach, March 2017 without flooding (left), and January 2019 during flooding (right)

Fig. 3 Building wall with markings of previous flood levels of the Neckar River in Eberbach, Germany (a), and a mitigation measure of the city: a power box located at two meters above ground level (b). The orange measuring rod in both photos is two meters long. Photographs by C. Klonner, Eberbach, July 2018 (a)

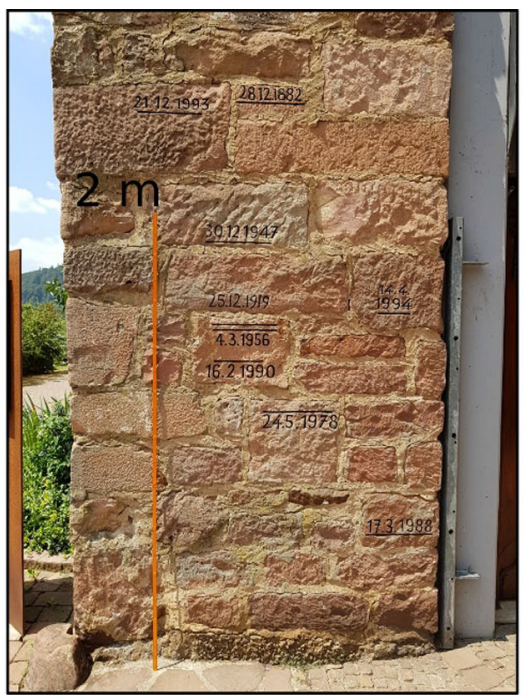

(b)

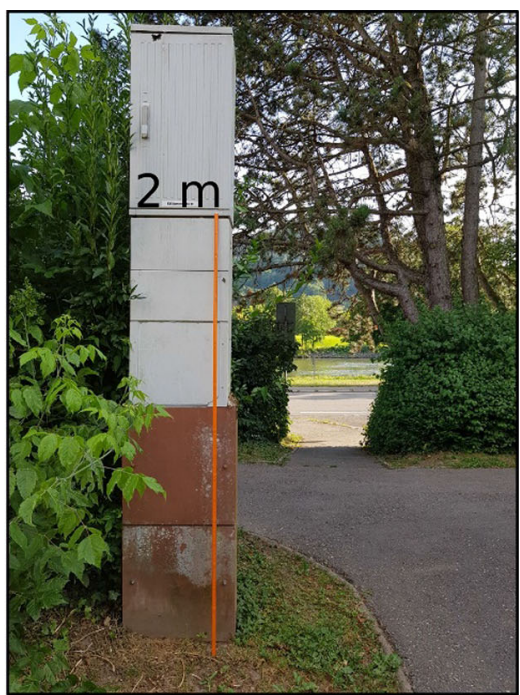

method based on paper and pen is an adequate way to include people who might not be familiar with the use of digital devices. Additional information from the participants can be gathered through questions in an accompanying survey.

In line with these requirements, the participatory approach of our study is based on paper sketch maps that are combined with a questionnaire. This approach makes it possible to capture local knowledge that is mostly not made visible. The following section outlines the two main methods of the study in more detail and provides more information about the flood maps we used for visual comparison. Table 1 presents an overview of the applied methods and tools as well as their application to the different tasks of the study.

\subsection{Sketch Maps}

The sketch maps are based on the OpenStreetMap Field Papers, ${ }^{1}$ which include data provided and edited by the public. The paper map is in DIN A4 $(21 \mathrm{~cm} \times 29.70 \mathrm{~cm})$ format and represents streets, buildings, and landmarks of the area. As there are influencing factors of the acquisition scale of the base map, that is, the level of detail of the area (Klonner et al. 2018), we used an overview base map of the whole city of Eberbach and a base map at the neighborhood level for both the study area and the control area, respectively (Fig. 4). We aimed at identifying the additional value of the two different spatial acquisition scales of the base map of the sketch maps, that is, an overview map with a larger area but less details and a neighborhood map with a smaller extent but more details. The study participants had to indicate their knowledge about floods in all three area maps, and they were asked to indicate in the base map

\footnotetext{
${ }^{1}$ http://wiki.openstreetmap.org/wiki/Field_Papers.
} 
Table 1 Methods and tasks applied during the different parts of the study in Eberbach, Germany

\begin{tabular}{|c|c|c|}
\hline & Methods and tools & Tasks \\
\hline \multirow[t]{5}{*}{ Survey preparation } & Field Papers webpage ${ }^{a}$ & Selection of areas for base maps \\
\hline & & - Study area \\
\hline & & - Control area \\
\hline & & - Overview Area \\
\hline & KoBo Toolbox webpage ${ }^{b}$ & Selection of questions for and design of questionnaire \\
\hline \multirow[t]{2}{*}{ Survey } & Printed base maps and pen & People mark areas that they perceive at flood risk \\
\hline & KoBo Toolbox app on tablet or smartphone & Researchers collect answers from participants \\
\hline \multirow[t]{4}{*}{ Data preparation } & Field Papers webpage & $\begin{array}{l}\text { Upload of photo/scan of the marked Field Papers and } \\
\text { download of the georeferenced file (GeoTIFF) }\end{array}$ \\
\hline & KoBo Toolbox webpage & Download of the questionnaire results \\
\hline & GIS & Digitizing of marking on sketch maps and saving as vector files \\
\hline & & $\begin{array}{l}\text { Combination of questionnaire results with corresponding sketch map } \\
\text { vector files }\end{array}$ \\
\hline \multirow[t]{2}{*}{ Analysis } & GIS & $\begin{array}{l}\text { Calculation of the number of participants for the marked areas with } \\
\text { respect to different characteristics based on the questionnaire }\end{array}$ \\
\hline & Reference data (flood map) & $\begin{array}{l}\text { Visual comparison of the flood maps based on the marking and the } \\
\text { reference flood map }\end{array}$ \\
\hline Results & GIS and Spreadsheet & Design of maps and diagrams according to the evaluation \\
\hline
\end{tabular}

ahttp://fieldpapers.org/

bhttp://www.kobotoolbox.org/

where they thought flood risk exists in these specific areas, that is, where the water might affect the city (Fig. 4). This knowledge may be based on previous experiences of floods but also on information provided by others. They used a colored pen to mark these parts in the paper maps. Cheung et al. (2016) collected flood risk perceptions with digital devices. We used paper maps (Curtis et al. 2014; O'Neill et al. 2015) to avoid the exclusion of people or respondents without the technical knowledge or equipment necessary to participate in a digital approach (Elwood et al. 2012).

The main advantage of the sketch maps based on Field Papers is the option of automatic georeferencing. As a result, time-consuming and error-prone manual georeferencing can be avoided, which makes it an easy-to-use tool, also applicable without specific geographic or technical knowledge. However, participants might draw wrong areas that are then used for further applications. This might be the case especially for pedestrians, who might not be very familiar with the local area. Therefore, it is important to check how many participants marked a specific area to identify such mistakes, and when using the results of the sketch maps, one has to keep in mind that such errors can occur.

This approach can also be used in areas where no other data are available for flood risk management, or in regions where it is difficult to capture such required data due to limited resources or difficult accessibility of the hazard area. Local communities can use this tool for their own disaster management. An image or scan of the marked sketch map is uploaded to the Field Papers webpage and then a georeferenced file (GeoTIFF) is downloaded into a GIS. The marked areas are digitized and saved in a GIS vector file as polygons. The individual results can be overlaid and the number of people marking the same area can be calculated and visualized.

The resulting maps enable the visualization of the knowledge of local citizens and make this information available for further uses in flood hazard analysis, for example, as a complement to authoritative data from flood gauges or from maps based on flood models.

\subsection{Questionnaire}

In addition to these maps, a questionnaire was used for evaluating the context. Respondents were asked about the place and duration of living in this area, the perceived flood intensity at three different areas (the exact location of the individual survey, the neighborhood, and the city), the strongest flood event they experienced, mitigation measures, information channels they use in the case of flooding, and some personal information, such as their age and gender.

The questionnaire was conducted by means of KoBo Toolbox, which allows the execution of both a digital and a paper-based survey. When the mobile application is used, the location of the questionnaire can be directly recorded and the combination with the sketch map is facilitated. Each sketch map is assigned a unique ID, which is also 
Fig. 4 Example of an overview and a neighborhood base map of Eberbach, Germany with the marking of participants in pink. Based on Field Papers (http:// fieldpapers.org/)
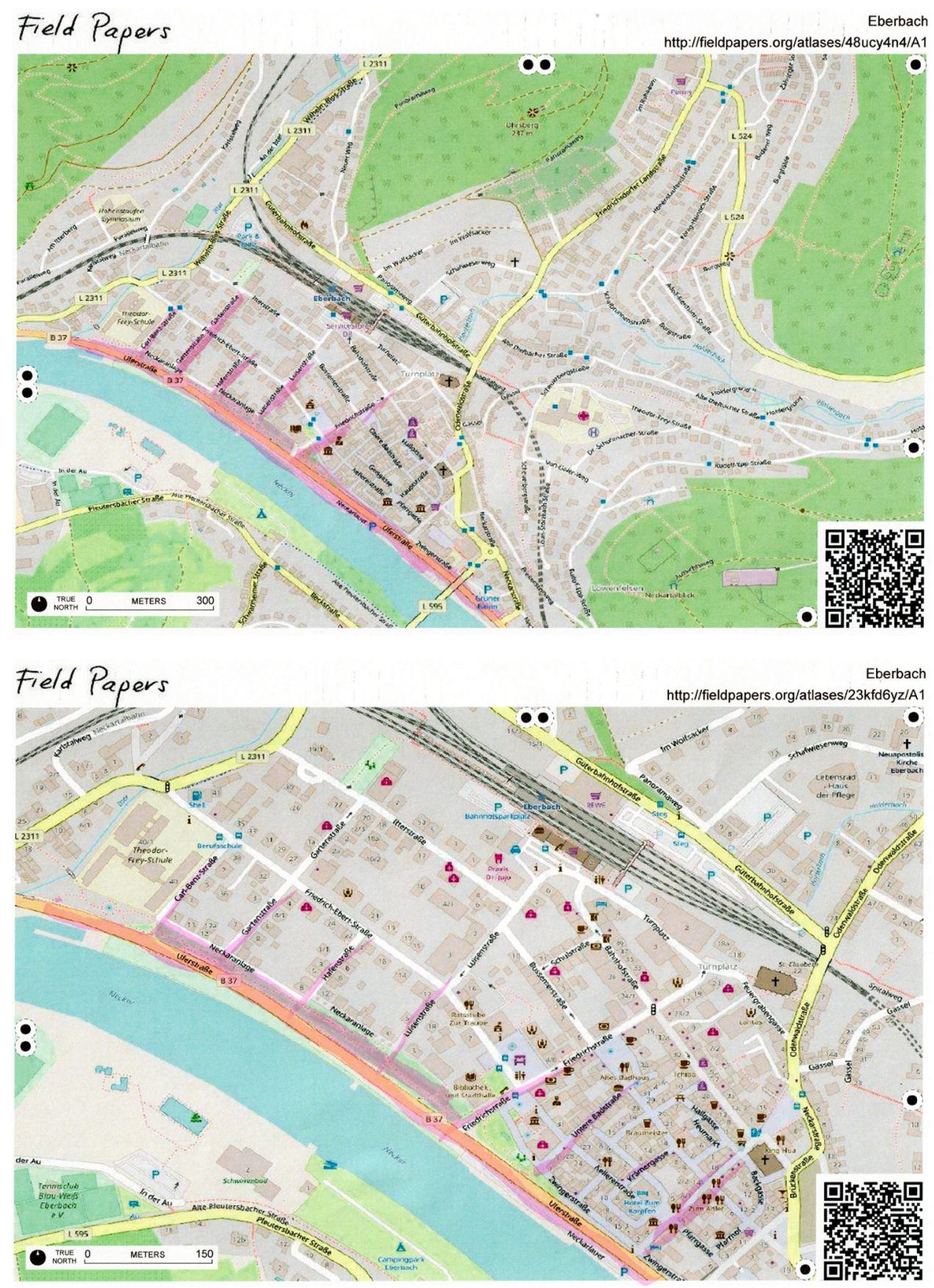

applied to the questionnaire. In addition to the marking of the sketch maps, the participants are also asked in the questionnaire about their knowledge of floods in the different parts of the city. They can choose from several pictures of a person with flood level markings and state their own estimation to which height the water can rise.

The Eberbach study, like our previous study in Santiago de Chile, takes influencing factors, such as property, into consideration, and there are two different scales of base maps (Klonner et al. 2016a). The overview base map represents a large part of the city of Eberbach, including the study area and the control area. The study area is located in the city center next to the Neckar and has a long history of flooding (see Sect. 3.3 for information about reference data, and Sect. 4.4 for a flood map of the study area). In contrast, the control area is located in a residential area in a part of the city that is not subject to flooding.

The sample size is based on information power (Malterud et al. 2016) instead of representativeness. We applied a purposive sampling and selected participants distributed over the sample areas to get an overview of flooding at several locations (Punch 2014, p. 164). Taking these 
aspects into consideration, 40 people in the study area and 40 people in the control area, who are either residents or pedestrians, were selected. Pedestrians who are living in another part of the city and who were passing by were questioned and residents were interviewed at the houses where they live. An equal number of surveys was conducted in each category. Residents were selected at random, though in a way to cover the extent of the study area. Because there might also be influencing social variables like wealth and education in specific parts of the sample areas, we selected participants in different sections of the sample areas (see Fig. 1) and of different age groups (Fig. 5). More than half of the participants, both of the study area and the control area, have lived in their respective neighborhoods for more than 10 years and have good experience with flooding in their areas.

In our further analyses, we focus on the differences between residents and pedestrians. Thereafter, we investigate the influence of the context by analyzing the sketch maps of residents who are owners of the property they live in and residents who rent. We also investigate the perceived flood intensity and contrast three different areas: the exact location of the individual participant survey, the surrounding neighborhood, and the whole city. In addition to the sketch maps, the answers to the question about perceived flood intensity give information about the risk evaluation. Participants can pick one of five options in a Likert-type scale ranging from not affected (1) to affected very strongly (5). We then compared the results of the sketch maps by participants of the study area with those by participants of the control area.

\subsection{Comparison with Flood Maps}

In addition to the internal comparisons between the study area and the control area, we visually identified similarities of the sketch map results and computed flood maps. We evaluated the data that resulted from the case study by conducting a visual comparison with the flood maps provided by the Landesanstalt für Umwelt Baden-Württemberg (LUBW), Germany. The different nature of the two datasets needs to be kept in mind during interpretation of the results. One is a dataset based on personal experience, and the other is an official dataset based on probabilities of flood events based on measured and physically modeled data. Therefore, we conducted a visual comparison of the two different types of flood maps. The overall area of local flood knowledge was compared to the specific area of the modeled flood data, and similarities as well as differences can be analyzed. The level of inherent detail can be compared within the two different datasets and gives insights into the applicability of the method.

\section{Results and Discussion}

In this section we present the results of our survey according to the previously stated objectives and focus on the design of the base map, the influence of participants' characteristics, and the similarities of the results in comparison to an authoritative flood map. Finally, we take a look at the results of the study in Santiago de Chile and discuss to what extent they resemble the results of the study in Eberbach.

\subsection{Base Map and Place of Living}

The results of the sketch maps in Fig. 6 reveal that there are no clear differences between the marking based on the two different scales of the base maps (overview and neighborhood maps). We conclude that in the case of river flooding in Eberbach the different acquisition scales of the base maps do not provide additional information because the marked flood areas are very similar.

These results can also be compared to pictures of a minor flood event in Eberbach in January 2019 (Fig. 7). The parking area and street next to the river are flooded and this is equivalent to the dark blue marking on the case study participant maps (Fig. 6).

Additionally, Table 2 shows that the residents tend to mark more areas at risk than the people passing by (pedestrians) if there are more than five participants in the study area mentioning it. However, if calculations are made based on participants in the control area outside the flood area, the opposite occurs (Table 2). A similar opposition is true for the neighborhood maps of the study area. Based on

\section{Participants}

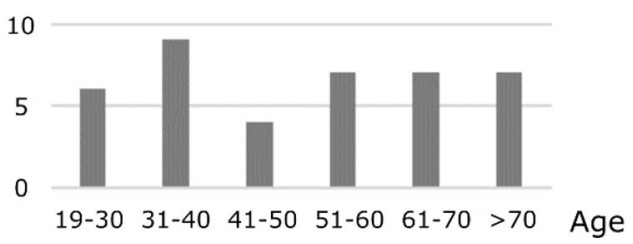

Participants

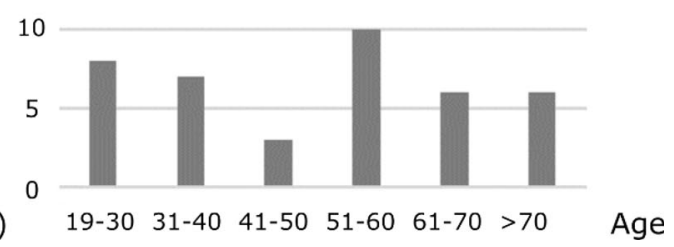

Fig. 5 Age of the participants in the study area, $n=40$ (a) and the control area, $n=40$ (b) 


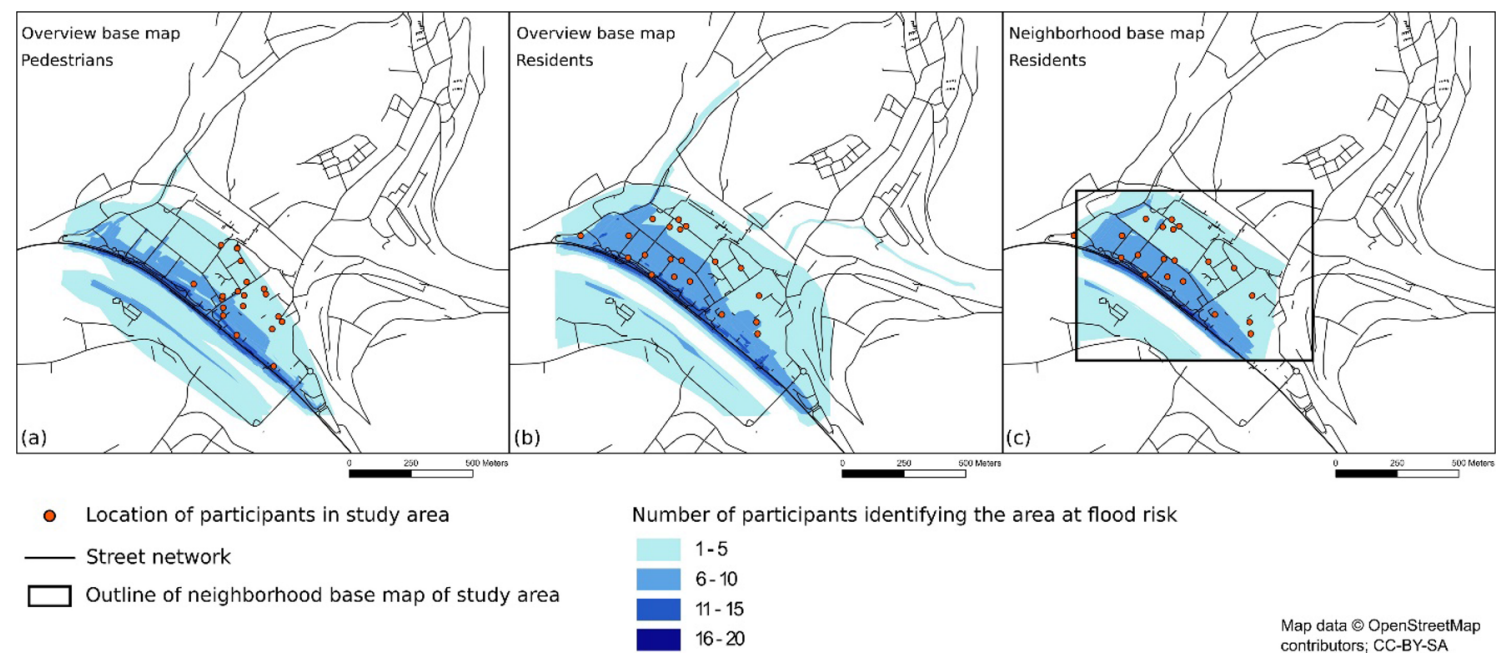

Fig. 6 Case study results of the flood risk study in Eberbach, Germany: Results of the sketch maps based on the overview maps (a, b) and the neighborhood maps (c). There are 20 participants in each group $(n=20)$. No clear difference according to the level of detail of the marking in the two different types of base maps. Additionally, the results of the study area are distinguished according to whether the participants are pedestrians passing by (a) or residents at the location of the survey $(\mathbf{b}, \mathbf{c})$. The residents tend to mark more areas at risk (b, c) than the pedestrians (a)

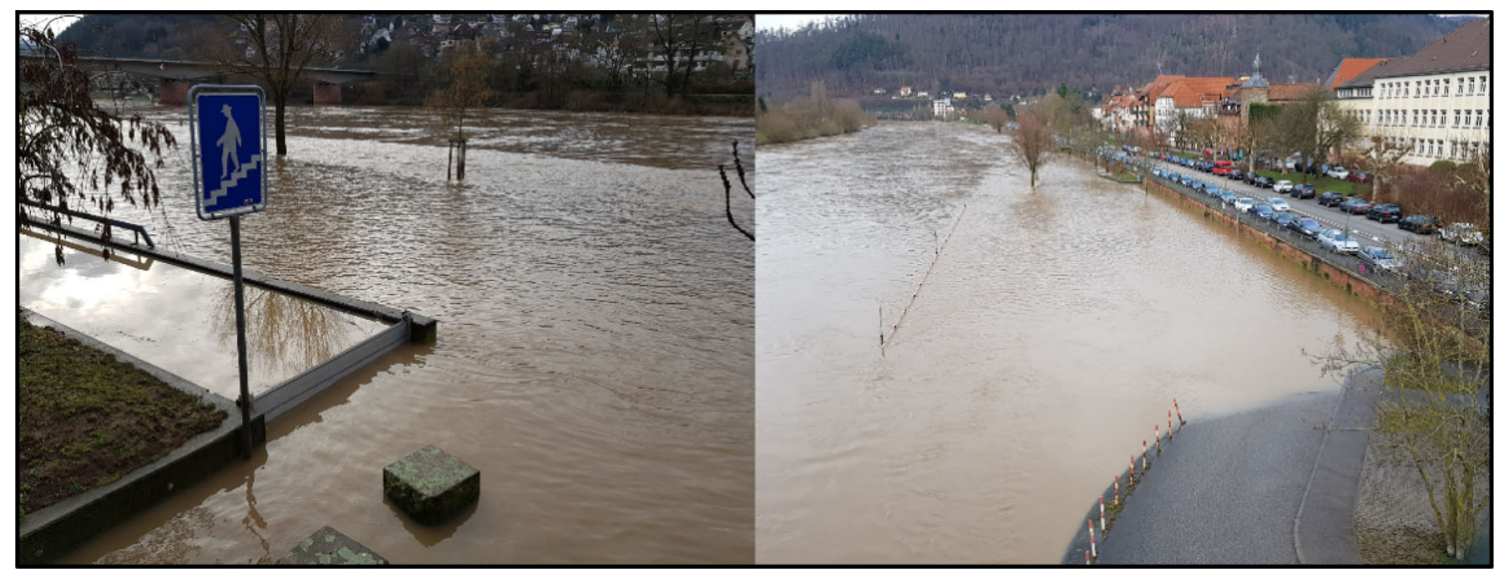

Fig. 7 Flooding of the parking area and street next to the Neckar River in Eberbach, Germany, during a minor flood event in January 2019. The flooded area coincides with the dark blue marking in the sketch maps in Fig. 6. Photographs by C. Klonner, Eberbach, January 2019

Table 2 Area at flood risk marked by the case study participants on the overview and the study area neighborhood base maps $\left(\right.$ in $\mathrm{m}^{2}$ ) in Eberbach, Germany. Residents in the study area identify more at risk areas than pedestrians. In the control area, the opposite is the case. We use the area identified by the residents in the study area as a reference $(100 \%)$ in order to clarify the differences between the results. Equal number in all groups $n=20$

\begin{tabular}{lllll}
\hline $\begin{array}{l}\text { Base map with } \\
n>5\end{array}$ & $\begin{array}{l}\text { Residents in study area } \\
\left(\mathrm{m}^{2}\right)\end{array}$ & $\begin{array}{l}\text { Pedestrians in study area } \\
\left(\mathrm{m}^{2}\right)\end{array}$ & $\begin{array}{l}\text { Residents in control area } \\
\left(\mathrm{m}^{2}\right)\end{array}$ & $\begin{array}{l}\text { Pedestrians in control area } \\
\left(\mathrm{m}^{2}\right)\end{array}$ \\
\hline Overview & $201,475(100 \%)$ & $136,008(68 \%)$ & $148,848(74 \%)$ & $187,726(93 \%)$ \\
Study area & $123,641(100 \%)$ & $49,252(40 \%)$ & $90,198(73 \%)$ & $128,537(104 \%)$ \\
\hline
\end{tabular}

these results, we deduce that the differentiation between residents and pedestrians needs to be expanded in future research to the concept of localness. In our study, pedestrians can still be residents of the city in general. Thus, it is necessary to identify their sense of belonging to the area. How much do they see themselves as part of the 
community and engage with mitigation measures or inform themselves about flooding in the area, for example?

\subsection{Property}

The property analysis shows that people with property mark a larger area when the area indicated on the base map of the study area is taken into consideration (Table 3). The area marked in the overview map is larger when marked by the participants without property because a few of them marked large areas (Fig. 8b). However, the number of participants identifying similar flood areas is higher when taking the people with property into account (Fig. 8a). This aligns with the findings of Wachinger et al. (2013), who stated that the personal experience of a hazard strongly influences risk awareness.

\subsection{Perceived Flood Intensity}

Figure 9 summarizes the results of the questionnaire regarding the perceived flood intensity, according to the different flood intensity levels and the location of the participants (study area or control area). These results show similarities to the evaluation of the areas by residents with property, where a larger area was identified by the residents from the control area (see Table 3), who also identified a higher level of intensity. It is surprising to see that the people who are living in the flood-prone areas and are regularly affected do not see their direct location as affected as their neighborhood or the city in general. This might be because of the mitigation measures they have undertaken (such as a cellar with only quickly removable items, a water pump, an elevated heating, and cellar walls painted with special oil paint), the feeling that they are prepared for a flooding, and that they know where to get information in a case of flooding. They feel safe and are aware of the fact that the local government is also supporting them. While they have a high risk perception of the area in general, they estimate the risk at their own location as lower due to their preparedness.

In contradiction to the fact that the participants in the study area, which is regularly affected by flooding, do not see their location as highly affected, they still indicate the possible flood level as very high. During the survey we used the image of a person with flood level markings, and the participants were asked to indicate based on their knowledge and experience to which height the water can rise at the location of the survey (Fig. 10). The majority chose the image with the highest level. Some of the participants even stated that if they had been given that option, they would have chosen a water level above the head. This shows again that they know about the flood risk and accept it and based on this awareness and their mitigation actions they do not perceive the risk as very high for themselves.

Another explanation for the results of our study may be an unrealistic optimism about future life events, which results in a tendency of people to rate their own chances of coming to harm as below average in the case of negative events and their chances of benefiting as above average in the case of positive events (Weinstein 1980). It might be the case that the participants are more optimistic about their own location than the location of other people's houses. Weinstein (1980) showed that there are five cognitive and motivational considerations that influence the level of optimistic bias. Personal experience can give a clearer picture of the events or decrease defensive denial, which can lead to less optimism about negative events. Other characteristics are perceived probability, degree of desirability, stereotype salience, and perceived controllability (Weinstein 1980). The results of Weinstein's study can also be used to interpret the outcomes of the study in Eberbach. Instead of exhibiting unrealistic optimism, the participants of the study area might have a lot more personal experience with flooding, and with that a more realistic picture of the risk for the city as a whole. Therefore, unrealistic optimism might be decreased. Similarly to Weinstein (1980), we conclude that more studies are necessary to analyze the relationship between self-protective behavior and unrealistic optimism because this relationship might strongly influence societal and individual vulnerability.

\subsection{Visual Comparison to Probabilistic Flood Maps}

The data collected with the sketch maps represent the local knowledge of citizens. In contrast, the Fig. 11 flood maps are based on authoritative data, such as historical records and physics-based flood modeling with a focus on flooded areas. There is a difference in concepts because the risk perception is rather a social construct, while the flood maps are based on measured and modeled data. Therefore, we avoided a direct calculated comparison and opted for a more general visual comparison in order to explore similar tendencies in the two different types of maps. The areas that are most often marked by the participants (dark blue areas in Figs. 6, 8) coincide with the regularly flooded areas in Eberbach based on data from the LUBW (dark blue areas in Fig. 11). The overall extent of the flooded area in the study area (Fig. 11b) has a comparable shape to the area marked by the participants (see Figs. 6, 8). As we particularly asked the participants to focus on the Neckar River, the sketch maps include little marking of the flooding based on the tributary rivers in the northern and eastern parts of Eberbach. Therefore, there are differences visible in the flood map in Fig. 11 because this map also 
Table 3 Area at flood risk marked by the case study participants on the overview and the study area neighborhood base maps (in $\mathrm{m}^{2}$ ) in Eberbach, Germany. Residents with property marked larger areas at risk than residents who rent. In the control area, the area marked by residents with property is even larger than that marked by those in the study area. We use the area identified by the residents with property in the study area as a reference $(100 \%)$ in order to clarify the differences between the results

\begin{tabular}{|c|c|c|c|c|}
\hline $\begin{array}{l}\text { Base map } \\
\text { with } n>5\end{array}$ & $\begin{array}{l}\text { Residents with property in } \\
\text { study area }\left(\mathrm{m}^{2}\right), n=8\end{array}$ & $\begin{array}{l}\text { Residents who rent in study } \\
\text { area }\left(\mathrm{m}^{2}\right), n=12\end{array}$ & $\begin{array}{l}\text { Residents with property in } \\
\text { control area }\left(\mathrm{m}^{2}\right), n=17\end{array}$ & $\begin{array}{l}\text { Residents who rent in } \\
\text { control area }\left(\mathrm{m}^{2}\right), n=3\end{array}$ \\
\hline Overview & $47,911(100 \%)$ & $20,511(43 \%)$ & $131,860(275 \%)$ & Max is $n=3$ \\
\hline Study Area & $30,729(100 \%)$ & $9118(30 \%)$ & $85,242(277 \%)$ & Max is $n=3$ \\
\hline
\end{tabular}
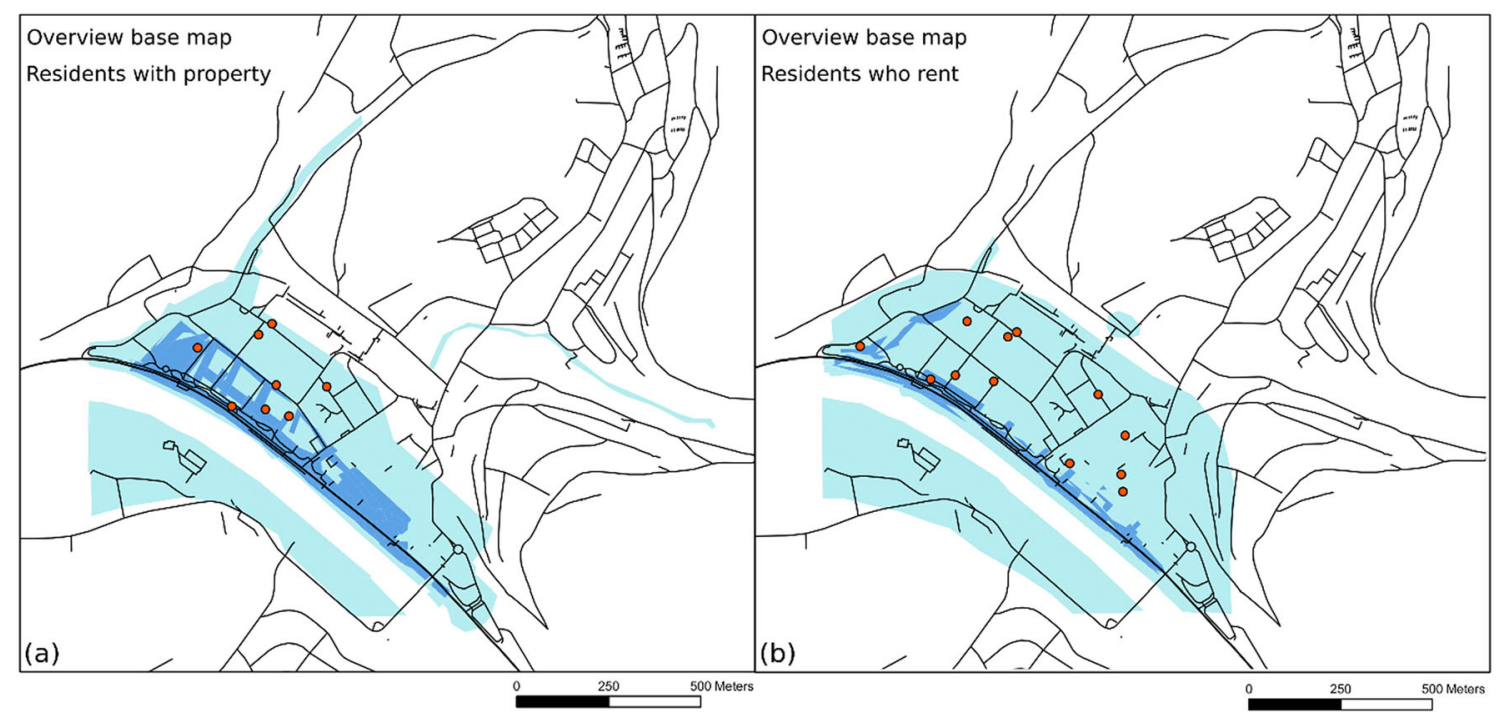

- Location of participants in study area

Number of participants identifying the area at flood risk
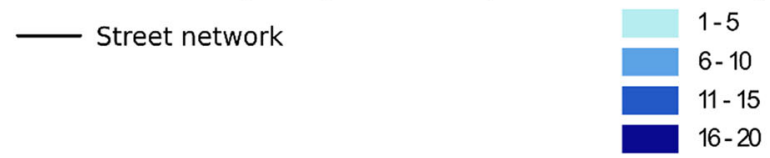

Map data $\odot$ OpenStreetMap contributors; CC-BY-SA

Fig. 8 Results of the sketch maps based on the marking on the overview base map by residents in the study area in Eberbach, Germany. The larger areas with darker colors show that more

includes the flooding related to the smaller rivers. The comparison, however, shows that the sketch maps can identify areas at flood risk that are officially indicated as flood risk areas as well.

\subsection{Comparison to Sketch Map Study in Santiago de Chile}

The analysis of the study in Eberbach shows that there is only a small additional value to the two different spatial scales of the base maps with respect to the level of detail of the resulting risk awareness maps (see Fig. 6). Only the area that is covered is different. In contrast, the case study in Santiago de Chile on urban flooding revealed that the neighborhood base maps lead to much more detailed information in comparison to the overview maps (Klonner residents with property $(n=8)$ (a) marked similar areas at risk than residents who rent $(n=12)(\mathbf{b})$

et al. 2018). This might be due to the fact that urban flooding is much more specific to certain streets in Santiago de Chile while river flooding in Eberbach usually covers a larger and connected area. Therefore, we suggest the use of the two different scales of the base maps in the case of urban flooding, while for river flooding, one base map level might be sufficient.

The comparison to the results of the study in Santiago de Chile (Klonner et al. 2018) shows how important the integration of the context is. The citizens in La Florida, Santiago de Chile, mentioned that the city is not doing enough to protect them. Certain measures are protecting some streets but only by leading the water into the neighboring areas (based on statements from participants in $\mathrm{La}$ Florida, Santiago de Chile, May 2016). This can be due to the fact that the city is rapidly growing, and therefore, the 
necessary mitigating measures have not yet been installed in an appropriate way. Moreover, the official information that the citizens have about floods seems rather sparse. New residents who recently moved to the flood-prone areas might not have any knowledge about the floods until they occur because the urban flooding is very specific to certain streets and there are no official flood maps available to the citizens in the area. A participant in La Florida stated that a neighbor sold his house, which is always affected by

\section{Participants in Study Area \\ Participants in Control Area}

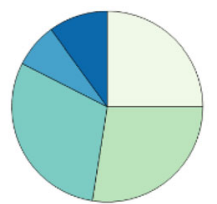

Direct Location
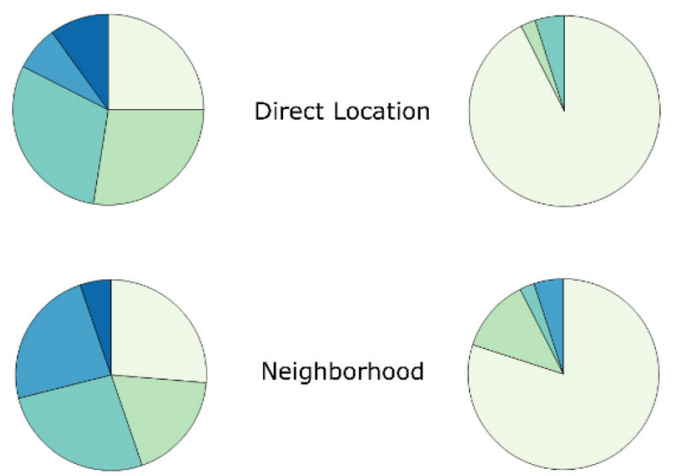

Neighborhood
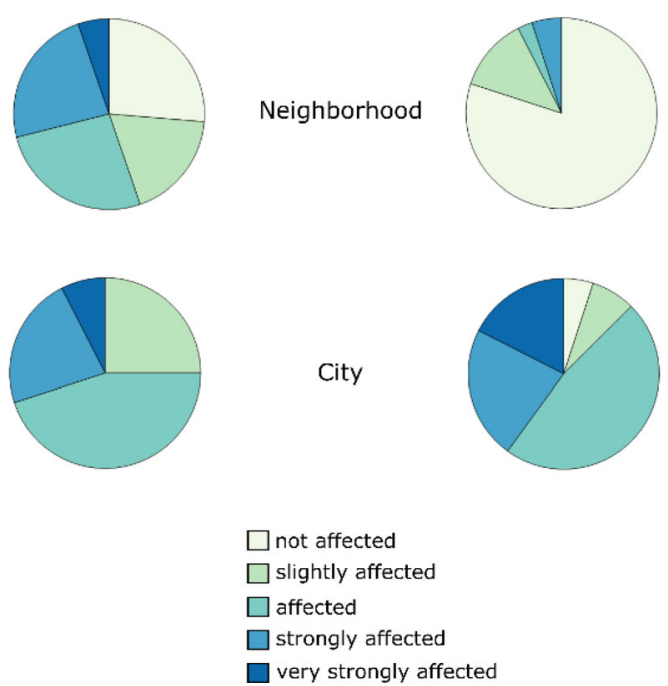

Fig. 9 The diagrams show the results of the flood intensity level investigation in Eberbach, Germany, and reflect how the case study participants perceive the city to be affected by flood. Participants of the study area see the city in general as more affected than their direct location. The participants of the control area rate their direct location as not much affected at all. They also see the city as much more affected flooding, without mentioning the flood risk, though the citizens themselves have a detailed knowledge of the floodaffected streets and areas in their neighborhood. Some homeowners installed protective measures such as small walls at the entrance of their houses, but in general, the researchers got the impression during their study that the participants do not take many preventive measures. The citizens in Santiago see the government as responsible for such interventions. The reason might be the poor socioeconomic conditions in this area. People cannot afford better and more measures and thus depend on the government to install the required mitigation measures such as an improved drainage system and retention areas.

In contrast, the citizens in Eberbach live with the flooding and they accept it as a part of their life. There is a long history of flooding and flood marks, which are installed all around the city, remind the citizens of the possibility of flooding. They know what to do in the event of flooding and they invest in private flood mitigation measures or support the official measures. They also have a good knowledge of where to get specific information in the case of flooding. An app of the city of Eberbach, for example, informs about flooding and the local government uses specific siren alarm signals to inform and warn people about impending flood levels. The citizens not living directly in the area at risk seem to have a higher risk perception of this area. In contrast, the people who face the flooding evaluate their flood risk as lower. Due to the experience they have, for example, in their own houses (Fig. 12), they know what to do in the case of flooding and they have prepared themselves. They have pumps to get rid of the water in their cellars or they rearrange the stored items so that no valuable belongings are in flooded parts of the house; some also use measures like tiling the cellar walls or painting them with special oil paint (Fig. 12).

In this way, residents reduce their vulnerability and do not see their surroundings at such a high flood risk. "We bought our house knowing about the flood risk. Our cellar is prepared accordingly, and we live with the flooding. We have a good neighborhood and help each other with
Fig. 10 The image of a person with flood level markings (1 to 6) was used for the study participants to indicate based on their knowledge and experience to which height the water can rise at the location of the survey. Most people chose the highest flood level from the six available options

\section{Flood level estimation based on image}

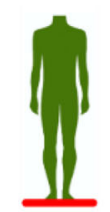

1

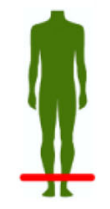

2

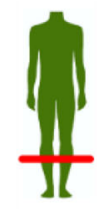

3

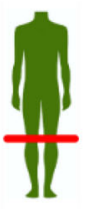

4

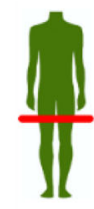

5

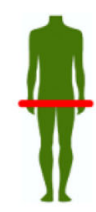

6

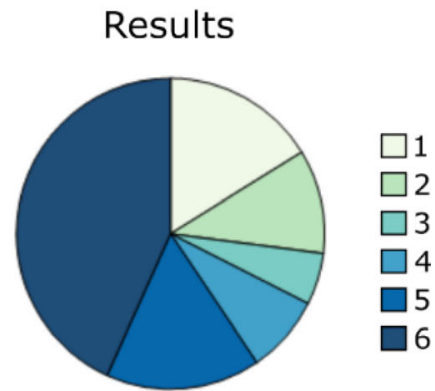




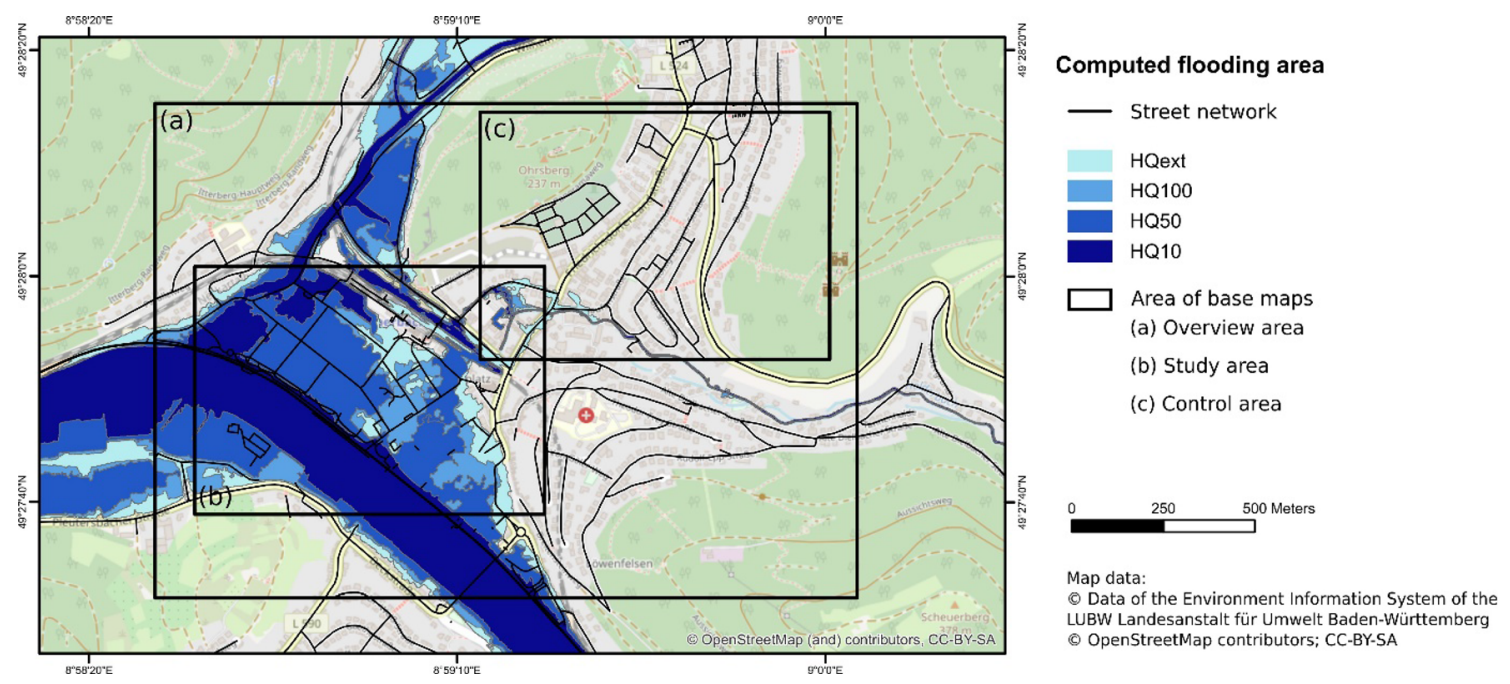

Fig. 11 Flood areas in Eberbach, Germany, based on authoritative data. Dark blue represents areas that are regularly flooded (HQ10 is a 10-year flood event), and light blue areas are only flooded in extreme events (HQext). The base maps of the sketch maps are indicated by (a), (b), and (c)

pumping. The city has a good routine with informing us and acting in cases of flooding. I feel safe" (Statement during the survey from a participant living in the flood area of Eberbach, June 2018). This illustrates that trust and adequate communication play an important role for flood risk perception. Seebauer and Babcicky (2017, p. 313) showed that "trust in the local governments, in volunteers in disaster management and relief services, and in neighbors affects how citizens perceive and act on flood risks." Volunteers are the most trusted group of these three and are considered as more competent regarding flood risk mitigation than the other two groups (Seebauer and Babcicky 2017). Unrealistic optimism (Weinstein 1980) and nonprotective responses are decreased while risk perception is increased by trust in volunteers (Seebauer and Babcicky 2017). There might, however, also be the case that too much trust in neighbors and local governments hinders one's own protective actions (Seebauer and Babcicky 2017).

The sketch map approach can support the risk communication between researchers, the local government, and the citizens, and trust can be increased. Klonner and Blessing (2019) showed a method for group discussions, which is based on the sketch map approach. Instead of the DIN A4 design of the map, they used a DIN A0 map in order to allow for a group of citizens as well as members of the local government to engage in the discussion. This format allows more insights into the risk perception as the communication might remind people of their own experiences, which they can combine on one common map (Klonner and Blessing 2019). This method also makes it possible to spatially target the risk communication on affected areas of the city, for example, during workshops.

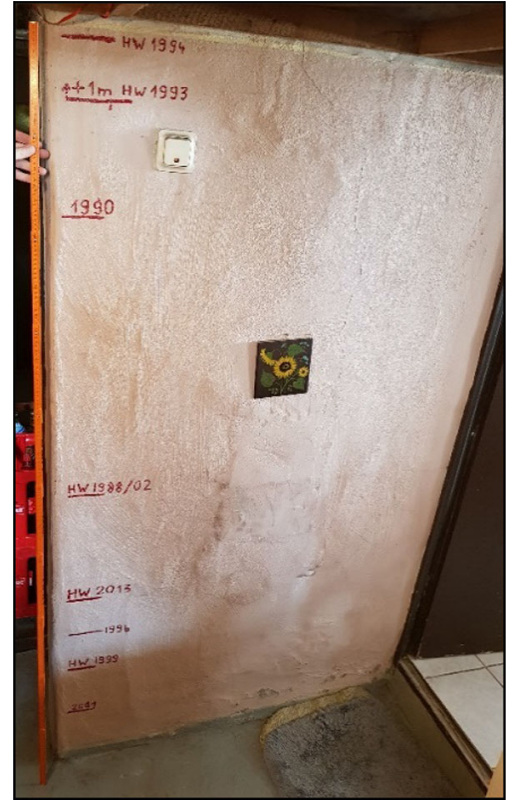

Fig. 12 Flood markings in the cellar of a study participant in the flood area in Eberbach, Germany. In 1993, the water filled the whole cellar and reached the first floor. The residents have painted their cellar with special oil paint and only store belongings in the cellar that can be removed easily. Photograph by C. Klonner, Eberbach, July 2018

The approach is based on open source software, and local governments can access this means for risk communication without additional monetary investment.

Overall, the results show that the sketch map method not only works for urban flooding, but also in cases of river flooding. The context of the citizens, however, plays an important role for the interpretation of the results of the sketch maps. 


\section{Conclusion}

In our study in Eberbach, we investigated a participatory approach that allows the inclusion of citizens in the DRR process, regardless of whether they have access to specific digital devices such as smartphones, knowledge about the usage of specific disaster-related systems, or the ability to access the Internet. We chose a paper-based approach, and local knowledge of the citizens was captured by drawings on these papers. In contrast to other studies (Haworth et al. 2016; Bustillos Ardaya et al. 2019) that focus on participatory methods within disaster risk management based on normal maps for the sketches, the sketches in our approach were made on OpenStreetMap Field Papers, which makes fast data processing possible because there is a base map and the drawings are already spatially correct. Moreover, the maps are georeferenced automatically, which saves time and error-prone manual data handling is not necessary. For a more adequate interpretation of the results, we implemented a questionnaire, which gave important additional insights into both the participants' knowledge about floods and their personal characteristics. It was possible to combine this information by means of a GIS and portray the results in maps according to the characteristics of the citizens. The information gained with the presented approach can be used for further DRR analyses, for example in addition to measured and simulated flood maps, and to support decisions about mitigation and preparedness measures.

Based on the comparison to a previous study in Chile (Klonner et al. 2018), we found that the spatial acquisition scale of the sketch maps plays a more important role for urban flooding than for river flooding because the latter may expand in a larger area, while urban flooding can be restricted to only a few streets. The base maps need to be selected accordingly and with the required level of detail of the results in mind. With respect to the personal background of the study participants, we concluded that people with property tend to have a higher risk awareness.

The results also show that the context of the participants is very important. The knowledge about flood risk and the acceptance of the situation can lead to personal mitigation actions and to trust in the government. This can reduce the vulnerability of the affected population and their risk; the people in flood-prone areas might have experience with floods in that area but they evaluate the risk at their own location as lower than in the neighborhood due to their feeling of preparedness. In line with these findings, we also concluded from our investigation of the differences between residents who live at the place of the individual survey and pedestrians who are passing by that it is important to take the feeling of belonging to a certain place into consideration. In how far do individuals identify with the location? And how much does this influence their risk perception and their risk evaluation?

The results showed that it is possible to adapt the methods that were used for another flood type and a different setting. The tools used in our study could also be applied within other scenarios such as for mapping the local knowledge about noise or for the identification of heat islands in urban areas. The application field is very broad, and the participants can have manifold backgrounds because the tools do not require specific skills. The participants can share their knowledge of their neighborhood in an easy way. Based on these data, additional measures can be taken into consideration. Furthermore, the approach can be used in DIN A0 format for group discussions in order to increase the risk communication between citizens, local governments, and researchers, which increases the trust among these groups.

Sketch maps in combination with questionnaires are only one example of a broad variety of means to disclose local knowledge. Future research should investigate the additional value of tools like interactive platforms that can combine knowledge captured with sketch maps together with official measurement data but also with more local information like image material provided by local citizens.

Acknowledgements We would like to thank the participants of our study for sharing their experiences and knowledge with us. Moreover, we thank the local authorities of the city of Eberbach for their information and support of this study. We would like to express gratitude to our colleagues from GIScience Heidelberg for their help during the data collection. We acknowledge the support of the WINKolleg of the Heidelberg Academy of Sciences and Humanities (HAW).

Open Access This article is licensed under a Creative Commons Attribution 4.0 International License, which permits use, sharing, adaptation, distribution and reproduction in any medium or format, as long as you give appropriate credit to the original author(s) and the source, provide a link to the Creative Commons licence, and indicate if changes were made. The images or other third party material in this article are included in the article's Creative Commons licence, unless indicated otherwise in a credit line to the material. If material is not included in the article's Creative Commons licence and your intended use is not permitted by statutory regulation or exceeds the permitted use, you will need to obtain permission directly from the copyright holder. To view a copy of this licence, visit http://creativecommons. org/licenses/by/4.0/.

\section{References}

Aerts, J.C.J.H., W.J. Botzen, K.C. Clarke, S.L. Cutter, J.W. Hall, B. Merz, E. Michel-Kerjan, J. Mysiak, et al. 2018. Integrating human behaviour dynamics into flood disaster risk assessment. Nature Climate Change 8(3): 193-199.

Assumpção, T.H., I. Popescu, A. Jonoski, and D.P. Solomatine. 2018. Citizen observations contributing to flood modelling: 
Opportunities and challenges. Hydrology and Earth System Sciences 22(2): 1473-1489.

Birkmann, J., and K. von Teichman. 2010. Integrating disaster risk reduction and climate change adaptation: Key challengesscales, knowledge, and norms. Sustainability Science 5(2): 171-184.

Botzen, W.J.W., J.C.J.H. Aerts, and J.C.J.M. van den Bergh. 2009. Dependence of flood risk perceptions on socioeconomic and objective risk factors. Water Resources Research 45(10): Article W10440.

Bubeck, P., W.J.W. Botzen, H. Kreibich, and J.C.J.H. Aerts. 2012. Long-term development and effectiveness of private flood mitigation measures: An analysis for the German part of the river Rhine. Natural Hazards and Earth System Sciences 12(11): 3507-3518.

Bustillos Ardaya, A., M. Evers, and L. Ribbe. 2019. Integrated participatory methodologies for disaster risk reduction: Tools to analyze complex systems through participatory processes in Brazil. In Strategies and tools for a sustainable rural Rio de Janeiro, ed. U. Nehren, S. Schlüter, C. Raedig, D. Sattler, and H. Hissa, 361-376. Berlin: Springer.

Cheung, W., D. Houston, J.E. Schubert, V. Basolo, D. Feldman, R. Matthew, B.F. Sanders, B. Karlin, et al. 2016. Integrating resident digital sketch maps with expert knowledge to assess spatial knowledge of flood risk: A case study of participatory mapping in Newport Beach, California. Applied Geography 74: 56-64.

Craglia, M., F. Ostermann, and L. Spinsanti. 2012. Digital earth from vision to practice: making sense of citizen-generated content. International Journal of Digital Earth 5(5): 398-416.

Curtis, J.W., E. Shiau, B. Lowery, D. Sloane, K. Hennigan, and A. Curtis. 2014. The prospects and problems of integrating sketch maps with Geographic Information Systems to understand environmental perception: A case study of mapping youth fear in Los Angeles gang neighborhoods. Environment and Planning B: Planning and Design 41(2): 251-271.

Dorn, H., M. Vetter, and B. Höfle. 2014. GIS-based roughness derivation for flood simulations: A comparison of orthophotos, LiDAR and crowdsourced geodata. Remote Sensing 6(2): $1739-1759$.

Eberbach. 2018a. Hochwasser/Wetter. http://www.eberbach.de/pb/ ,Lde/260581.html. Accessed 4 Apr 2018.

Eberbach. 2018b. Zahlen/Daten/Fakten. http://www.eberbach.de/pb/ ,Lde/265205.html. Accessed 4 Apr 2018.

Elwood, S., M.F. Goodchild, and D.Z. Sui. 2012. Researching volunteered geographic information: Spatial data, geographic research, and new social practice. Annals of the Association of American Geographers 102(3): 571-590.

Ferster, C.J., and N.C. Coops. 2014. Assessing the quality of forest fuel loading data collected using public participation methods and smartphones. International Journal of Wildland Fire 23(4): 585-590.

Gaillard, J.C., and J. Mercer. 2013. From knowledge to action: Bridging gaps in disaster risk reduction. Progress in Human Geography 37(1): 93-114.

Goodchild, M.F. 2007. Citizens as sensors: The world of volunteered geography. GeoJournal 69(4): 211-221.

Haworth, B.T., E. Bruce, J. Whittaker, and R. Read. 2018. The good, the bad, and the uncertain: Contributions of volunteered geographic information to community disaster resilience. Frontiers in Earth Science 6: Article 183.

Haworth, B., J. Whittaker, and E. Bruce. 2016. Assessing the application and value of participatory mapping for community bushfire preparation. Applied Geography 76: 115-127.

Hirsch Hadorn, G., H. Hoffmann-Riem, S. Biber-Klemm, W. Grossenbacher-Mansuy, D. Joye, C. Pohl, U. Wiesmann, and
E. Zemp (eds.). 2008. Handbook of transdisciplinary research. Bern, Switzerland: Springer.

Horita, F.E.A., L.C. Degrossi, L.F.F.G. Assis, A. Zipf, and J. Porto de Albuquerque. 2013. The use of volunteered geographic information and crowdsourcing in disaster management: A systematic literature review. In Proceedings of the Nineteenth Americas Conference on Information Systems, 15-17 August 2013, Chicago, Illinois, USA, 1-10.

Klonner, C., and L. Blessing. 2019. Gathering local knowledge for disaster risk reduction: The use of sketch maps in group discussions. In Proceedings of the 16th International Conference on Information Systems for Crisis Response and Management, 19-22 May 2019, Valencia, Spain, 1397-1398.

Klonner, C., S. Marx, T. Usón, and B. Höfle. 2016a. Risk awareness maps of urban flooding via OSM field papers-Case study Santiago de Chile. In Proceedings of the13th International Conference on Information Systems for Crisis Response and Management, 22-25 May 2016, Rio de Janeiro, Brasil, 1-14.

Klonner, C., S. Marx, T. Usón, J. Porto de Albuquerque, and B. Höfle. 2016b. Volunteered geographic information in natural hazard analysis: A systematic literature review of current approaches with a focus on preparedness and mitigation. ISPRS International Journal of Geo-Information 5(7): Article 103.

Klonner, C., T. Usón, S. Marx, F.-B. Mocnik, and B. Höfle. 2018. Capturing flood risk perception via sketch maps. ISPRS International Journal of Geo-Information 7(9): Article 359.

Malterud, K., V.D. Siersma, and A.D. Guassora. 2016. Sample size in qualitative interview studies: Guided by information power. Qualitative Health Research 26(13): 1753-1760.

Marana, P., L. Labaka, and J.M. Sarriegi. 2018. A framework for public-private-people partnerships in the city resilience-building process. Safety Science 110(Part C): 39-50.

O’Neill, E., M. Brennan, F. Brereton, and H. Shahumyan. 2015. Exploring a spatial statistical approach to quantify flood risk perception using cognitive maps. Natural Hazards 76(3): $1573-1601$

Polanyi, M. 1966. The tacit dimension. Chicago and London: University of Chicago Press.

Punch, K.F. 2014. Introduction to social research: Quantitative and qualitative approaches. London: Sage.

Reichel, C., and U.U. Frömming. 2014. Participatory mapping of local disaster risk reduction knowledge: An example from Switzerland. International Journal of Disaster Risk Science 5(1): $41-54$.

Seebauer, S., and P. Babcicky. 2017. Trust and the communication of flood risks: Comparing the roles of local governments, volunteers in emergency services, and neighbours. Journal of Flood Risk Management 11(3): 305-316.

Shi, J., V.H.M. Visschers, M. Siegrist, and J. Arvai. 2016. Knowledge as a driver of public perceptions about climate change reassessed. Nature Climate Change 6: 759-762.

Singh, D. 2011. The wave that eats people-The value of indigenous knowledge for disaster risk reduction. Geneva: United Nations Office for Disaster Risk Reduction. https://www.unisdr.org/ archive/21236. Accessed 9 Dec 2019.

Soden, R., N. Budhathoki, and L. Palen. 2014. Resilience-building and the crisis informatics agenda: Lessons learned from open cities Kathmandu. In Proceedings of the 11th International Conference on Information Systems for Crisis Response and Management, 18-21 May 2014, University Park, Pennsylvania, USA.

UNDRR (United Nations Office for Disaster Risk Reduction). 2019a. Hyogo Framework for Action (HFA) and Sendai Framework for Disaster Risk Reduction. https://www.unisdr.org/we/coordinate. Accessed 23 Mar 2019. 
UNDRR (United Nations Office for Disaster Risk Reduction). 2019b. Terminology on disaster risk reduction. https://www.unisdr.org/ we/inform/terminology. Accessed 8 Jan 2020.

Usón, T.J., C. Klonner, and B. Höfle. 2016. Using participatory geographic approaches for urban flood risk in Santiago de Chile: Insights from a governance analysis. Environmental Science \& Policy 66: 62-72.

Wachinger, G., O. Renn, C. Begg, and C. Kuhlicke. 2013. The risk perception paradox-Implications for governance and communication of natural hazards. Risk Analysis 33(6): 1049-1065.
Wagner, K. 2007. Mental models of flash floods and landslides. Risk Analysis 27(3): 671-682.

Weinstein, N.D. 1980. Unrealistic optimism about future life events. Journal of Personality and Social Psychology 39(5): 806-820.

Yumagulova, L., and I. Vertinsky. 2019. Moving beyond engineering supremacy: Knowledge systems for urban resilience in Canada's Metro Vancouver region. Environmental Science \& Policy 100: 66-73. 